\title{
Organizational resilience: Nonprofit organizations' response to change
}

\author{
Hope Witmer $^{\mathrm{a}, *}$ and Marcela Sarmiento Mellinger ${ }^{\mathrm{b}}$ \\ ${ }^{a}$ Urban Studies Department and Centre for Work Life and Evaluation Studies (CTA), \\ Malmö University, Malmö, Sweden \\ ${ }^{\mathrm{b}}$ School of Social Work, University of Maryland, Baltimore County, Baltimore, MD, USA
}

Received 2 April 2015

Accepted 13 July 2015

\begin{abstract}
.
BACKGROUND: Organizational resilience refers to the ability to respond productively to significant disruptive change and transform challenges into opportunities. There is a gap in the literature about resilient nonprofit organizations and its application for identifying organizational conditions for successful adaption to external variables that threaten their existence. OBJECTIVE: The aim of this study was to identify organizational characteristics that point to the resilience of nonprofit behavioral healthcare organizations as they successfully adapt to funding changes.

METHODS: A multiple case study of two behavioral health nonprofit organizations was conducted. Data was collected through interviews and focus groups, and analyzed through a qualitative content analysis.

RESULTS: Using the framework of resilience, six themes that equipped these organizations to successfully adapt to funding changes were identified. They included: commitment to the mission, improvisation, community reciprocity, servant and transformational leadership, hope and optimism, and fiscal transparency.

CONCLUSIONS: The findings suggest that incorporating these qualities into an organizational system equips it to systematically adapt to funding changes and other disruptive challenges. Using resilience as a process and not simply an outcome after recovery, nonprofit organizations can have the capacity to continuously respond to challenges and provide uninterrupted and valuable services to society.
\end{abstract}

Keywords: Resilience, nonprofit leadership, organizational adaptability, healthcare

\section{Introduction}

Interest in organizational resilience has grown as businesses and nonprofit organizations pursue new strategies for becoming sustainable in a rapidly changing funding world and a turbulent economic environment $[1,2]$. In addition to reduced resources there is increased regulatory requirements and greater competition to remain fiscally viable and socially relevant [3]. Organizations that are resilient have the

\footnotetext{
*Address for correspondence: Hope Witmer, Ph.D, Urban Studies Department and Centre for Work Life and Evaluation Studies (CTA), Malmö University, 20506 Malmö, Sweden. Tel.: +46 040665 8689; E-mail: hope.witmer@mah.se.
}

capacity to adapt and more easily stay relevant and responsive to market changes $[4,5]$. Academic and business interest of organizational resilience continues to grow, however it has been primarily viewed as an organizational outcome with a focus on how organizations effectively recover from adversity $[1,2]$. The processes and capabilities of how organizations 'do' organizational resilience have largely remained unexplored. This research addresses this gap by analyzing how resilience is constructed within an organization from a management and employee perspective.

Organizational resilience refers to an organization's ability to adapt to internal and external disturbances, 
maintain its integrity as a system, re-organize itself, and increase its capacity by transforming challenges into opportunities for learning and innovation $[2,6$, 7]. Hamel and Valikangas [4] call this the resilience gap - the space between the rapid pace of change in the environment and the organization's ability to adapt. To better understand this gap in the nonprofit sector, this study explores the resilience of two nonprofit behavioral healthcare organizations. The aim of the study was to identify organizational characteristics that point to the resilience of these organizations as they successfully adapted to funding changes.

\section{Organizational context}

The industry of behavioral healthcare (a continuum of services for mental and emotional wellbeing for individuals at risk for mental, behavioral, or addictive disorders) has been impacted by economic, political, and consumer demands that challenged healthcare delivery structures and threatened economic viability for many healthcare service providers [8]. Healthcare reform and managed care requirements made it more difficult to receive financial reimbursement for services and increased the competition for resources between agencies $[9,10]$.

Faced with this changing environment, many nonprofit behavioral healthcare organizations responded by downsizing their workforce, restructuring, and forming alliances and mergers as strategies to increase their economic viability [11]. In addition to streamlined and efficient systems, nonprofit behavioral healthcare organizations needed the ability to assess the potential impact of the changes, and needed to respond quickly without changing their essential function as an organizational system [3,7]. They also needed the capacity to maintain their mission and provide consistent services to their communities while retaining fiscal viability [2]. In response to the constantly changing environment, nonprofit behavioral healthcare organizations need more than a onetime strategy to adapt; they require the resilient capacity to be novel and imaginative as they operate in uncertain and fluctuating environments.

\section{Organizational resilience}

Resilience is a fundamental quality that can apply to individuals, groups, organizations, and systems that respond productively to significant disruptive change [12]. It is a multidisciplinary whole systems approach that includes aspects of psychology [13], ecology [14, 15], organizational theory [5], and community studies and economics [16].

Resilience is a dynamic process that infers a symbiotic relationship within the system, and between the system and its environment. It is grounded in the study of ecological systems theory [15, 17], and includes the psychological capacity to adapt to highly stressful long term conditions [13]. When applied to an organization, it implies the ability to adapt to internal and external demands and concurrently transform these challenges into opportunities for learning and innovation $[2,3]$.

The study of organizational resilience is the study of the interaction of multiple parts of a system responding collectively to an external stimulus, especially unexpected emergent events [18]. Using general systems theory as a framework, these are dynamic interactions that occur within an organization and between the organization and its environment [17]. Westley [7], states that system resilience lies in the continuous movement through a cycle of adaptation and transformation. He further purports that a serious loss of system resilience only happens when the system gets trapped at some point in the cycle. Dervitsiotis [19] defined the point where an organization is impacted by an environmental shift as the strategic inflection point. As a result of the impact of this change on the system, new rules and assumptions alter the operating cognitive and structural expectations for the system. The routine predictable behaviors and the symbiotic relationships within an organization that create and maintain mutual dependence are described as the dynamics maintaining the system's integrity. According to this theory, by coordinating the system components, a resilient organization has the capacity to respond to the shifting external environment while maintaining internal system integrity $[5,20]$.

Organizational resilience is a complex phenomenon that includes inter- and intra- system dynamics, the exploration of psychological and interpersonal processes, and structural components that contribute to system integrity $[3,5,20]$. It is a constant process that includes the reconstruction of organizational values, processes, and behaviors [4], and the analysis of vision, values, elasticity, empowerment, coping, and connections on both an individual and organizational level $[7,21,22]$.

Little research is available on organizational resilience application to nonprofit organizations. More recently, the concept of resilience has been applied to 
the application of social innovation to build institutional resilience at the critical inflection point where a system is stuck [7]. However, there is a gap in the literature on the application of the theoretical framework of resilience for identifying organizational conditions for successful adaption to external variables that threaten the existence of the organization [1]. In this study, resilience was used as a framework for understanding how the organizations adapted to funding changes in the context of unpredictable external conditions. The main research question answered in this study was: What organizational characteristics present in these nonprofit behavioral healthcare organizations point to their resilience when successfully adapted to funding changes? The inclusionary criterion for an organization's ability to successfully adapt to funding changes was fiscal viability as indicated by sustained or increased total revenue over a five-year time period, and sustained or increased service to the community as indicated by number of patients served during the same five years.

\section{Method}

\subsection{Sample}

The sample for this multiple-case study consisted of two nonprofit, private, behavioral healthcare organizations in the Northeast region of the United States. These two organizations were selected through a purposive sample because they were identified as being successful in adapting to the funding changes associated with transitioning to a managed healthcare delivery structure. The data for the inclusion criterion (sustained or increased revenue and sustained or increased number of patients served during the same five consecutive years) were gathered from the organizations' financial and patient admission records.

A purposive selection of informants was used to create groups representing different levels in the organization - executive management, middle management, and employees providing direct patient care. Approval for the study was granted by the IRB. All participants signed a consent form prior to participating in the study. Twenty-four individuals participated in the study. The process for selecting the participants was as follows. The Chief Executive Officer (CEO) of each organization was interviewed. As a part of the interview process, a request to conduct focus groups with the organizations' executive leadership teams was made. Both CEOs agreed to the focus groups with their executive teams. The entire executive team at each organization agreed and participated in the focus groups. Using snowball sampling, the 10 executive team members were asked to identify managers to be interviewed; these were individuals they defined as key organizational informants who constructively adapted to change in their respective organizations $[23,24]$. Due to duplication of selection by the executive team, seven managers were identified, contacted, and interviewed. At the conclusion of the manager interviews, snowball sampling was used to identify direct care employees to be interviewed. These were employees the managers identified as key organizational informants who constructively adapted to change. The suggested employee informants were contacted and all agreed to participate in the interviews. All participants interviewed had been employed by the organization a minimum of one year and were between the ages of 24-60. The sample consisted of 17 men and 7 women. Twenty-two of the participants were Caucasian, one was an African American male, and one a Hispanic male. Two of the individuals interviewed provided perspectives broader than their role as an agency employee. One was a previous board member, and the other was a part time employee and director of an outside community agency. The interviews occurred in person, at each person's place of employment. The reason participants were selected from all levels in the organization is based on the premise that if an organizational system is resilient, then organizational members at all levels of the system will identify the same or similar resilient characteristics for the organization.

\subsection{Data collection and analysis}

Yin's [24] case study method utilizing a multiple case design was used with two agencies sharing similar characteristics and mission. This approach was selected because it examines a case in depth, within its real life context, and to explore causation in order to find underlying principles. Replicating the process in two agencies provided similar and more robust results to understand the underlying principles of organizational resilience within the context of changing healthcare conditions. Yin's [24] method allows for using theoretical constructs to guide inquiry; using resilience as a theoretical framework, this study explored if characteristics indicating an organization's ability to adapt to the changing environment were present. 
Data were collected through semi-structured interviews and focus groups. Two focus groups were carried out with the executive team at each organization. One focus group was conducted with the four members of the executive leadership team from one agency; the other focus group was conducted with the six members of the second organization's executive leadership team. The individual interviews were carried out with three members of the executive leadership team, seven program managers (four from one agency and three from the other agency), and seven direct care staff (four from the one agency and three from the other agency). A total of 17 individual interviews were conducted. Seven people participated in both, a focus group and an interview.

The interviews and focus groups were conducted in the span of three months, and they lasted up to one and one half- hours. The interviews were semi-structured and open-ended. The purpose of the interviews was to gather data about the interviewee's perceptions of organizational responses to funding changes. The interview included six open ended, semi-structured questions about resilience including how they define resilience, a descriptive assessment of their organization's level of resilience, and the opportunity to provide an example of how the organization responded when faced with a funding change. The interview questions were developed for the purpose of initiating, but not limiting, dialogue about adaptation in response to funding changes. The questions were created considering the theoretical propositions [24] of organizational resilience by Coutu [20] and Weick [25]. For example, Coutu's focus on values was used and Weick's use of the concept of bricolage as a theoretical frame for adaptation was also used (bricolage is the ability to problem-solve and create order out of chaos, by improvising with available resources [25].) Questions asking about their general thoughts on resiliency, if they saw their organization as resilient, and how the organizations adapted to changes were asked. Because questions were used only as a guide, the interviewer presented the questions and asked clarifying questions to encourage dialogue and acquire additional information. Table 1 provides a list of the interview questions with examples of responses.

The interview and focus group data gathered from each organization were then analyzed by means of a qualitative content analysis [26]. The purpose of the data analysis was the categorization and interpretation of collected data into predominant themes. What follows is a description of the data analysis process.
The transcribed interviews were read through carefully a number of times in order to gain an overall view of the interview material and to begin the process of coding and categorizing the data into predominant themes [24, 27]. Consistent with Yin's [24] method, theories of organizational resilience were utilized for the organization of the intial data. The data were then coded by thematic content. The coded data were then arranged into categories for the purpose of identifying emerging themes, patterns and relationships between categories [26, 27]. There were two steps to the data analysis coding process, open coding and axial coding. Open coding was used to closely examine and analyze the text from the focus groups and individual interviews. Using Coutu's [20] and Weick's [25] findings as guidance for the initial codes, the information was divided into categories [27]. As additional information was gathered, it was compared to the existing categories. Information gathering and comparison continued until no new information was added to the existing data $[23,24]$. The purpose of open coding was to divide the data into predominant themes that began to descibe the phenomena being studied. The themes continued to be developed and information continued to be gathered until the categories were saturated and primary themes of successful adaptation to funding changes began to emerge. When the primary categories had been identfied, axial coding was introduced [27]. Axial coding was used to explore the interrelationships of categories and their influence on the central phenomonenon of organizational resilience. This process identified predominant themes regarding organizational resilience for both organizations. After the data were coded and categorized, a cross case analysis occurred $[23,24,26]$. The themes and patterns that occured in both organizations were identified as primary categories of resilience [23, 25, 27]. Seventeen resilient organizational categories were identified; these were reduced to six primary characteristics. Analysis of the collected data was ongoing throughout the data collection process.

\section{Findings}

The aim of this study was to identify organizational characteristics that point to the resilience (ability to adapt in a changing environment) of two nonprofit behavioral healthcare organizations. Six characteristics emerged from the data: (a) A commitment to the mission of the organization, (b) ability to improvise 
Table 1

Interview questions and sample responses

Questions Used
1. What do you think about when I state the
word resilience?
word resilience?

2. In your opinion is the organization you are a part of a resilient organization? Why or why not?

3. Can you recall a story that provides an example of organizational resilience in action in your organization?

4. Funding changes can be, a change in funding source, change in reimbursement rate, or an increase in expenses.

Can you describe an example(s) of a time that the organization improvised, or did not improvise when faced with a funding change?

5. Can you talk about how the organization remains aware of and adaptes to shifts in the environment that could impact the organization?

6. Is there anything I missed that you would like to add about resilience and your organizaition's ability adapt to funding changes?
Sample Responses

"The ability to persevere through times of chaos."

"A proactive approach to bad news."

"The ability to proactively respond to the ebbs and flows of change"

"The ability to be nimble, getting in and out of ventures that are not profitable and doing that quickly."

"Part of what has helped us, is that years ago we adapted a business strategy of collaboration vs. competition. People value what we do and look at us as partners and as a result we get information before other providers. I am amazed at what people share with us. There is trust and there is a different philosophy than other agencies that have been forced to have programs that have waiting lists, just to confirm that they have a good product. People have a sense that we want to hear what they have to say and people know we have an open attitude."

"We started new programs to meet community needs. Such as the adult partial program, wrap around services and family based services. We got in late on the last one but we knew it was something we had to do. We hit a lot of barriers but once the doors were opened we were prepared to walk through them. It was a fast growing service and there were a lot of other things going on but we hired someone who had expeirence and could help us keep moving."

"We partnered with an existing insurance company and created a new business to be guaranteed managed care referrals"

"When insurance went up by a million dollars we cut costs, no raises, nothing in 401-Ks cut back on expenses. We also had to do lay offs and restructuring to accommodate changing reinbursements structures."

"We also have continued to diversify our programs so that we are not dependent on one source of revenue."

"We did not respond quickly enough in our accounts receivable department. There was not the expertise or appropriate systems to manage the volume and as a result we lost a lot of revenue. We recovered but it was challenging."

"We have staff strategically involved in the county, state and local level that are hearing about things and bringing that back to the agency."

"We hired someone that had worked for a health insurance company. He has worked with the managed care companies and he has maintained those relationships."

"We are also a part of many networks and organizations that provide healthcare policies and procedues where we can get information."

"As I think of the leadership team we all share a focus of looking for opportunities. We never say "this is horrible" instead we are looking for a better way to work something out or develop a new program or we look for a positive solution."

"We are not concerned about turf or egos and it feels really safe and it affects resilience because you can be creative." using existing resources, (c) reciprocal relationship with the community based on mutual trust, (d) a servant and transformational leadership style, (e) a shared cognitive perspective of hope and optimism, and (f) fiscal transparency. The supporting data from the interviews are presented in this section. Table 2 provides a list of the six categories and representative content for each category.

\subsection{Mission}

It is clear from the data that there was a strong commitment to the mission of the organization. Exec- utives, managers, and direct care staff expressed a commitment to the purpose of the organization as described in the organizations' mission statements. A middle manager stated "I believe that the majority of the people here are driven by the mission and that is what keeps people here; that is what keeps the spirit [of the organization] alive." The commitment to the mission statement concurs with one of the three primary categories of Coutu's [20] model of resilient organizations. According to Coutu [20], resilient organizations have a clear mission statement and organizational members share in a deep belief in the value of the organization's purpose. The missions 
Table 2

Resilient qualities identified and sample interview responses

\begin{tabular}{|c|c|}
\hline Resilient qualities & Sample interview responses \\
\hline 1. Mission: Strong comittment to mission & $\begin{array}{l}\text { "I believe that the majority of the people here are driven by the } \\
\text { mission and that is what keeps people here, that is what keeps the } \\
\text { spirit of the organization alive." }\end{array}$ \\
\hline \multirow[t]{2}{*}{ 2. Improvisation } & $\begin{array}{l}\text { "With any new contract or potential new program we look at how } \\
\text { we can use the resources we have. Then we look at the } \\
\text { community and other programs to see if we can be creative." }\end{array}$ \\
\hline & $\begin{array}{l}\text { "We do well at responding to external needs; like the extended } \\
\text { acute unit. In a few months we adapted and changed things both, } \\
\text { internally and externally." }\end{array}$ \\
\hline 3. Community reciprocity & $\begin{array}{l}\text { "The county looks at us as the place to start programs. They view } \\
\text { us as reilable and innovative" }\end{array}$ \\
\hline 4. Servant and transformational leadership & $\begin{array}{l}\text { "There is opportunity for people to see that they can do things } \\
\text { differently. They are empowered, we didn't propose how, they } \\
\text { took ownership and initiated looking for opportunities, and they } \\
\text { are excited." }\end{array}$ \\
\hline 5. Fiscal transparency & $\begin{array}{l}\text { "We hold our program managers fiscally accountable and we equip } \\
\text { them with fiscal knowledge and the connetion to services that are } \\
\text { offered so that they can explain and educate their employees. } \\
\text { This helps us to be resilient because everyone is aware and on the } \\
\text { same page fiscally. Program managers sign off on budgets, } \\
\text { everyone is looking at program and revenue so it becomes a } \\
\text { shared responsibility." }\end{array}$ \\
\hline 6. Hope and optimism & $\begin{array}{l}\text { "As I think of the leadership team we all share a focus of looking } \\
\text { for opportunities. We never say "this is horrible" instead we are } \\
\text { looking for a better way to work something out or develop a new } \\
\text { program or we look for a positive solution." }\end{array}$ \\
\hline
\end{tabular}

of both organizations were clear and concise. Many organizational members connected personally and professionally with the mission because their values were congruent with the organizations' stated values. The following quote illustrates this point "[The agency] has a clear mission statement and those who have been here a long time have adopted the mission from a professional and personal perspective." Another employee further explained, “... because the organization is a spiritually-based, religiouslyoriented institution, people are committed to the mission statement and helping others as a part of their personal value system.” This concurs with Kaplan's [28] theory that in nonprofits, many people become a part of the organization because of a personal connection with the mission of the agency.

Responses indicated that some were committed to the mission based on the founding religious values of the organization, while others for altruistic reasons. Although there were different reasons for connecting to the mission, employees were able to clearly articulate it and shared a common commitment to participating in its fulfillment and in the purpose of the organization. As a result, there was a commitment to finding a way to maintain the mission when the organization was challenged, thereby contributing to the organizations' resilience.
Although, most participants' statements added to the themes found in the study, a few expressed their disagreement. One person thought the organization's commitment to the mission was weak by stating:

I think that [the mission] has been heavily eroded around here. When I first started here there was a lot more of that type of feeling [commitment to the mission] but if anything when you get to the people who actually work on the floors there is more of a cynicism about the mission. It is on paper and verbally expressed, but the actions of the organization don't reflect that.

\subsection{Improvisation}

Shifting community demands, a volatile healthcare environment, and unstable financial indicators all contributed to the need for both agencies to innovate and improvise [10]. The combined forces created what one interviewee identified as urgency.

The data showed that both organizations rated the ability to improvise, in response to funding changes, as high. Organizational improvisation was defined by participants as the ability to utilize existing resources, such as adapting physical space and sharing staff between programs. For example, one participant 
stated "With any contract or new program, we use what we have in place now and then we look at what is needed above and beyond." To stay viable, both organizations adapted quickly to the many shifting variables by improvising and being creative with existing resources. This became an organizational norm when working with external agencies as well as managing internal resources. As stated by one participant:

When we meet with other constituents we are talking about how we can use existing resources to meet the needs; for example, all the services we provide in the schools. We can figure out how to pay for part or all of it, or we partner and they provide space and we swap resources by providing services at no charge for them.

The broader healthcare environment and erratic financial indicators initiated the drive to be innovative in order to stay viable in a competitive market place. Both behavioral healthcare organizations in this study responded by utilizing and sharing existing resources in their programs, between programs, and between agencies. The sharing of resources was an adaptive mechanism that equipped these organizations to be resilient as they responded to a volatile healthcare environment that was in the process of redefining the distribution of resources.

As was the case with data gathered on the mission, there was one participant who thought the organization was inflexible and did not manifest the characteristics mentioned by those that are willing to improvise in order to adapt to their environment. This person said:

I remember being surprised that we are still in the game because when I think of the organization, I think of resistance to change. But somehow it seems to work.

\subsection{Community reciprocity}

Informants from both organizations identified the reciprocal, collaborative, symbiotic relationship with the community as an important quality in the organizations' ability to adapt to funding changes. Both organizations were characterized as open organizational systems with flexible boundaries [17]. There were multiple examples where they would take in information from the external environment, evaluate its fit with their mission, and then adapt accordingly. This capacity contributed to the organizations' resilience.
As stated by one organizational member

I think that our reputation helps us be resilient, probably in an indirect way, but I think when funding streams are threatened, our relationships with counties ... certainly helps. We also seem to be asked to run pilot programs and programs that are needed because we usually do a good job... so we are resilient as far as having the trust and faith of our payers that we can do it.

The word trust was used frequently to describe the relationship between the agencies and their surrounding communities. One participant stated:

Part of what has helped us is adapting a business strategy, years ago, of collaboration vs. competition. People who value what we do look at us as partners, and as a result we get information before other providers. I am amazed at what people will share with us. There is trust.

The trust between the agencies and their communities was based on years of cultivating community relationships, and an honest assessment of the organizations' ability to provide services. The credibility of trust was further strengthened by the organizations' declination, when capabilities were lacking, to successfully provide services. As described by one organizational member: "We are responsive and honest with what we can and cannot provide. This breeds respect because others see that we don't promise what we can't provide just to get money."

This builds trust and further reciprocity between the organizations and their communities, and contributes to organizational resilience.

\subsection{Servant and transformational leadership}

Participants described the leadership style of their organization as non-ego motivated, mission focused, and collaborative. One person described the leadership as "Not concerned about turf or egos and it feels really safe and it affects resilience because you can be creative. In other places ego and protecting self has hindered the organization from doing what the organization needs to do".

Collaborative problem solving was encouraged, and organizational leaders were challenged to focus on organizational goals and the mission of the organization, not individual promotion. Participants described the leadership style as "... not hierarchical; it is relational. We are committed to the relationship and to each other." In both agencies, col- 
laborative strategies were encouraged, and the focus was on promotion of organizational goals and mission, not individual promotion. As indicated in the interviews, the employees felt supported by their leaders and the attitude of servant leadership was pervasive through all levels of the organization $[29,30]$.

There were two organizational attributes in these organizations that created an environment conducive to this style of leadership. The first was the leadership philosophy rooted in a religious tradition of service that values qualities of servant leadership [29]. The second was the commitment to the organization as an extension of employees' personal value systems. According to the theory of transformational leadership, when an organizational leader taps into individuals' morals and values and engages them in a collective vision, a lasting, sustainable transformation is created, which is characteristic of a resilient organization [31, 32].

There was one dissenting voice regarding collaborative, value-based leadership. The statement made by this participant infers a hierarchical versus a collaborative leadership model and a lack of leadership sophistication. The participant stated:

One of the problems with not-for-profit leadership is that we stink at leadership and the problem is we can't admit that we stink at it. It is the classic denial. It is hard for us to admit that we stink.

\subsection{Fiscal transparency}

The data indicated that both organizations had fiscal transparency, and that this contributed to their resilience. This included open written and verbal communication about business decisions, regular meetings that communicated the fiscal status of the organizational operations to all employees, and transparent processes regarding strategies for programs that were not fiscally profitable. As described by one participant “... part of resilience is just how well people understand the input that affects financial results."

The interviewees identified a distinction between understanding, accepting, and adapting to the realities of the marketplace, which required internal adjustments. Understanding the marketplace entails an external focus and awareness of the external environment. The interviewees concluded that once the organization was aware of upcoming or current changes, they quickly responded and adapted. "Part of resilience is growing programs that are success- ful and trimming programs that are not successful." "Leadership is tough as nails. They are responsive. They won't coddle you but will make tough decisions that keep us making money."

In contrast, they identified that the organizations were not as quick at identifying internal systems to be modified to support the changes. The result was internal processes that were not sophisticated enough to handle the required managed care processes. As an example, the organizations' accounts receivable systems were not re-structured to handle the increased volume, and resulted in significant financial loss. Both organizations recognized the need to strengthen internal accountability systems after major impacts to the system affected profitability.

\subsection{Hope and optimism}

The data identified attitudes of hope and optimism by organizational members at both organizations. When talking about challenges, the interviewees emphasized a focus on opportunities instead of an emphasis on barriers and limitations. Organizational members viewed setbacks as temporary but surmountable. They also recognized the organizations' ability to convert challenges into opportunities for growth and development. One participant stated, "People have a cognitive focus on opportunities and look for positive solutions." Another said, "Resilience is dealing with reality from the standpoint of let's look for the opportunities in this."

Accompanying this attitude was the belief that the organization would continue to serve the community regardless of challenges and obstacles. One person said:

Part of our mission that gets tied in here is the concept of 'finding a better way.' That is a part of our philosophy and that philosophy leads an organization in being resilient. That is part of the founding philosophy, to find a better way, and that continues to serve us and I tie that with mission.

Another participant stated:

If you talk with some of our people who have been here a while, we may say 'it is hard but let's keep going'. Believing in the cause and looking for ways for it to happen. Possibilities-thinking and not getting bogged down with the "can'ts." This way of thinking is pervasive from the founding fathers to the existing people. 
The research indicated that the founders of the organizations and organizational members, including executive leaders, managers, and direct care staff, all identified a resilient attitude of hope and optimism as the expected response to challenges, and therefore, an attribute of the organizations' culture [33]. In these organizations, hope and optimism appeared to be how organizational members made sense of change, informed their responses, and contributed to resilience [32]. This framework resulted in organizational members who were cognitively prepared to adapt to the many changes that affected the organizations.

\section{Discussion}

These findings suggest that the resilient characteristics displayed by these organizations equipped them to productively respond to the disruption of funding changes. Supporting research shows that organizations that are resilient can adapt to market changes and can stay relevant within their organizational environment $[4,5]$. The capacity to improvise with existing resources ("bricolage"), commitment to mission/core values, community reciprocity, and hope/optimism, which were identified in this study, were also found to be present in organizations in Mallak [34, 35], Coutu [20], Weick [5] and Stephenson's [36] studies on organizational resilience. Although the terminology may not be exactly the same, these characteristics point to common themes present in resilient organizations. Another important distinction that has implications for future comparative research is that these studies are not limited to not-for-profit organizations, but represent a mix of characteristics across not-for-profit and for-profit organizations in multiple sectors.

Using the theoretical framework of resilience, this study provided insight into the interactions within the organizational system [14] and into how the system responded as a whole to the external environment [6]. This is noteworthy because resilience has mainly been studied as an outcome of organizations' recovery from hardship [1,2]. This study, however, provides both, a theoretical framework for understanding organizational adaptability through the frame of resilience, and the identification of how organizations actually 'do' resilience, thereby viewing this concept as a process and not simply an outcome. This also sheds light on the importance of the manager's resilience as both an individual resource that contributes to the doing aspects in the organization and as part of his/her leadership function, thereby contributing to the organization's resilience as a whole [31]. The organizations in this study found ways to weather the changes in their environment before getting to a devastating point from which they needed to recover. Resilience was demonstrated through the process of using innovative strategies, drawing on community reciprocity, maintaining fiscal transparency, and promoting hope and optimism among employees, supporting Westley's [7] idea that system resilience is inherent in the continuous movement through a cycle of adaptation and transformation.

Maintaining system integrity is a central concept in resilience theory [5, 20]. This is an important issue for nonprofit organizations as they are continuously faced with the challenges of an uncertain financial environment [37]. While this study shows these characteristics point to the organizations' resilience process, it is possible they did not consciously use these strategies, together, as a process, to maintain their integrity and viability. The characteristics identified here can, therefore, provide future insight into how nonprofit organizations can maintain their integrity. If organizations can use resiliency as a process, they should be able to provide needed services without changing their essential functions, increase their capacity by being innovative, and strengthen the symbiotic relationships they cultivate. Because nonprofit organizations are a vital part of the social, economic, and political development of society [38], it is imperative that we understand the processes they use to stay viable.

Although six characteristics emerged as indicators of resilience, it is important to note that they were present together in both organizations. Within the resilience framework, not one single characteristic could, in and of itself, maintain the integrity of each organization. These characteristics function together in strengthening the organizational system and its interactions with its outside environment. However, each of these areas could be further explored to identify their unique contribution to organizational resilience.

\section{Limitations}

Several limitations should be taken into consideration. First, the sample was small, making generalization of the results to similar organizations difficult. Second, snowball sampling was used 
to identify key organizational informants. This process could limit the selection process to only those who would present the organization positively. Additionally, as with most research, it is important to acknowledge the possibility of introducing bias into the study - bias from the researchers' point of view, as well as from the self-reported data provided.

\section{Conclusion and implications for practice and research}

The aim of this study was to identify resilient organizational characteristics present in two nonprofit behavioral healthcare organizations that successfully adapted to funding changes. Successful adaptation was defined as the organizations having sustained or increased total revenue over a five-year time period, and sustained or increased service to the community as indicated by the number of clients served during the same five years. Six major characteristics emerged from the data. The findings suggest that these characteristics could be used to develop theory and strategies to anticipate and productively respond to unexpected change. These strategies could be implemented tactically at a senior leadership level, and operationally at a management level. It is important to note that these results were consistent across all levels of employees in the organization and that four (commitment to the mission, improvisation, and community reciprocity, hope and optimism) of the six qualities concur with existing theories of organizational resilience.

The preliminary and limited size of the study prohibits strong conclusions. However, expanding the research by exploring each of the six characteristics of resilience and testing it in the broader nonprofit arena could further define resilient qualities unique to this sector, add to the findings in this study, and contribute to the existing body of literature on organizational resilience. Furthermore, a comparison of resiliency between for-profit and not-for-profit organizations to examine any possible cross over between resilient qualities in the for-profit and not-for-profit sector should also be done. This would contribute to what is presently a gap in the literature. Possibly the most salient contribution of this research is the implication that incorporating these qualities into an organizational system equips it to systematically adapt to funding changes and other disruptive challenges. By using resilience as a process and not simply an outcome after recovery, nonprofit organizations can have the capacity to continuously respond to challenges and provide uninterrupted and valuable services to society.

\section{Conflict of interest}

The authors have no conflict of interest to report.

\section{References}

[1] Duchek S. Growth in the face of crisis: The role of organizational resilience capabilities. Acad Manage Proc 2014;861-6.

[2] Zolli A, Healy AM. Resilience: Why things bounce back. New York, NY: Simon and Schuster; 2013.

[3] Kimberlin S, Schwartz SL, Austin MJ. Growth and resilience of pioneering nonprofit human service organizations: A cross-case analysis of organizational histories. Journal of Evidence Based Social Work 2011;8(1-2):4-28.

[4] Hamel G, Valikangas L. The quest for resilience. Harvard Business Review 2003;8(9):52-64.

[5] Weick K, Sutcliffe K. Managing the unexpected: Resilient performance in an age of uncertainty. 2nd ed. San Francisco, CA: Jossey-Bass; 2007.

[6] Folke C. Resilience: The emergence of a perspective for social-ecological systems analyses. Global Environmental Change 2006;16(3):253-67.

[7] Westley F. Social innovation and resilience: How one enhances the other. Stanford Social Innovation Review 2013;11(3):28-39.

[8] Mendel P, Scott WR. Institutional change and the organization of health care. In: Bird CE, Conrad P, Fremont AM, Timmermans, F. editors. Handbook of Medical Sociology. 6th ed. Nashville TN: Vanderbilt University Press; 2010.

[9] Furrow BR, Greaney TL, Johnson SH, Jost TS, Schwartz RL. Health law cases, materials and problems. 4th ed. St. Paul, MN: West Group; 2001.

[10] Galvin TL. Examining institutional change: Evidence from the founding dynamics of U.S. health care interest associations. Academy of Management Journal 2002;45(4): 673-96.

[11] Zimmerman B, Dooley K. Mergers versus emergers: Structural change in healthcare systems. Emergence 2001;3(4): 65-82.

[12] Horne JF, Orr JE. Assessing behaviors that create resilient organizations. Employment Relations Today 1998;24(4): 29-39.

[13] Masten AS. Ordinary magic: Resilience processes in development. American Psychologist 2001;56(3):227.

[14] Holling CS. Understanding the complexity of economic, ecological, and social systems. Ecosystems 2001;4(5):390405.

[15] Walker B, Holling CS, Carpenter SR, Kinzig A. Resilience, adaptability and transformability in social-ecological systems. Ecology and Society 2004;9(2):5.

[16] Levin SA, Barrett S, Aniyar S, Baumol W, Bliss C, Bolin B, Sheshinski E. Resilience in natural and socioeconomic systems. Environment and Development Economics 1998;3(2):221-62.

[17] Bertalanffy L. General system theory: Foundations, development, applications. Revised ed. New York: George Braziller, Inc; 1969. 
[18] Lissack MR, Letiche H. Complexity, emergence, resilience, and coherence: Gaining perspective on organizations and their study. Emergence, a Journal of Complexity Issues in Organizations and Management 2002;4(3):72-94.

[19] Dervitsiotis KN. The pursuit of sustainable business excellence: Guiding transformation for effective organizational change. Total Quality Management 2003;14(3):251-67.

[20] Coutu DL. How resilience works. Harvard Business Review 2002;80(5):46-55.

[21] Mallak L. Putting organizational resilience to work. Industrial Management 1998;40(6):8-13.

[22] Siebert A. The resiliency advantage: Master change, thrive under pressure, and bounce back from setbacks. New York: Berrett-Koehler Publishers, Inc; 2005.

[23] Babbi E. The practice of social research. 9th ed. Belmont, CA: Wadsworth/Thompson Learning; 2001.

[24] Yin RK. Case study research: Design and methods. 5th ed. Thousand Oaks, CA: Sage; 2014.

[25] Weick KE. The collapse of sensemaking in organizations: The Mann Gulch disaster. Administrative Science Quarterly 1993;38(4):628-52.

[26] Creswell JW. Qualitative inquiry and research designing: Choosing among five traditions. 1998.

[27] Strauss A, Corbin J. Basics of qualitative research tecniques and procedures for developing grounded theory. 2nd ed. Thousand Oaks, CA: Sage Publications; 1998

[28] Kaplan RS. Strategic performance measurement and management in nonprofit organizations. Nonprofit Management and Leadership 2001;11(3):353-70.

[29] Greenleaf RK. Servant leadership. New York: Paulist Press. 1977.
[30] Muller J, Maclean R, Biggs HC. The impact of a supportive leadership program in a policing organisation from the participants' perspective. Work: A Journal of Prevention, Assessment \& Rehabilitation 2009;32(1):69-79.

[31] Schmidt B, Loerbroks A, Herr R, Litaker D, Wilson M, Kastner M, Fischer J. Psychosocial resources and the relationship between transformational leadership and employees' psychological strain. Work: A Journal of Prevention, Assessment \& Rehabilitation 2014;49(2):315-24.

[32] Sommer SA, Howell JM, Hadley CN. Keeping positive and building Strength the role of affect and team leadership in developing resilience during an organizational crisis. Group \& Organization Management 2015;1-31. DOI: $10.1177 / 1059601115578027$

[33] Schein EH. Defining organizational culture. In: JS Ott, editor. Classics of organization Theory. 4th ed. New York: Harcourt Brace College; 1985.

[34] Mallak, LA. Toward a theory of organizational resilience. In Management of Engineering and Technology. Technology and Innovation Mangement. PICMET'99. Portland International Conference 1999;1:223.

[35] Mallak, L. Measuring resilience in health care provider organizations. Health Manpower Management 1998;24(4): 148-52.

[36] Stephenson A, Vargo J, Seville E. Measuring and comparing organisational resilience in Auckland. Australian Journal of Emergency Management 2010;25(2):27-32.

[37] Salamon LM. The state of nonprofit America. 2nd ed. Washington, DC: Brookings Institution Press; 2012.

[38] Hasenfeld Y. Human services as complex organizations. Thousand Oaks, CA: Sage Publications; 2010. 